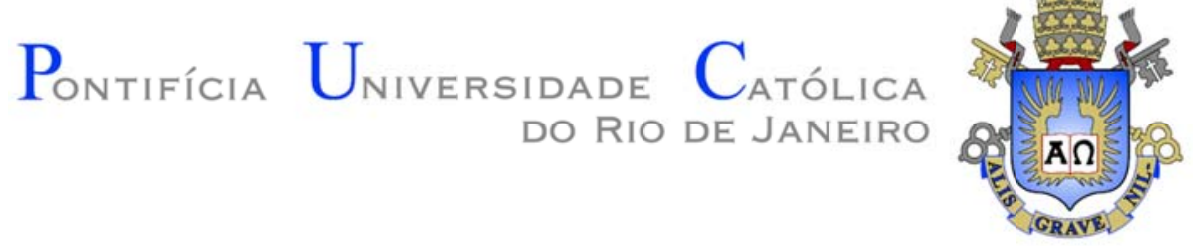

Ítalo Linhares Salomão

\title{
Análise numérica da eficiência de lajes
} nervuradas tridirecionais

\section{Dissertação de Mestrado}

Dissertação apresentada como requisito parcial para obtenção do grau de Mestre pelo Programa de Pósgraduação em Engenharia Civil da PUC-Rio.

Orientador: Profa. Marta de Souza Lima Velasco

Co-Orientador: Profa. Elisa Dominguez Sotelino 


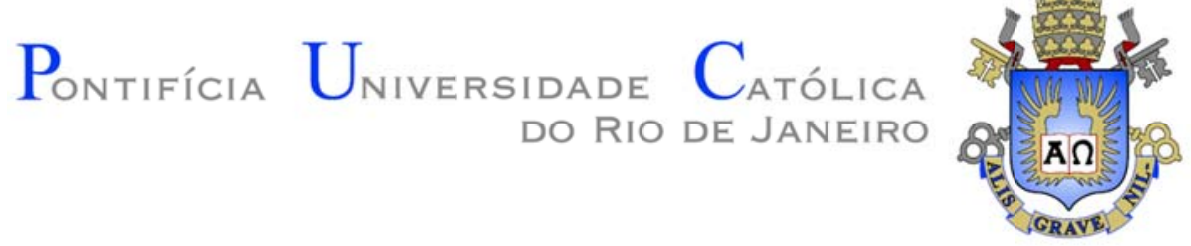

Ítalo Linhares Salomão

\section{Análise numérica da eficiência de lajes nervuradas tridirecionais}

Dissertação apresentada como requisito parcial para obtenção do grau de Mestre pelo Programa de Pósgraduação em Engenharia Civil do Departamento de Engenharia Civil do Centro Técnico Científico da PUCRio. Aprovada pela Comissão Examinadora abaixo assinada.

Profa. Marta de Souza Lima Velasco

Orientadora

Departamento de Engenharia Civil - PUC-Rio

Profa. Elisa Dominguez Sotelino

Co-Orientadora

Departamento de Engenharia Civil - PUC-Rio

Prof. Júlio Jerônimo Holtz Silva Filho

Departamento de Engenharia Civil - PUC-Rio

Prof. Eduardo César Cordeiro Leite

Universidade de Fortaleza

Prof. José Eugenio Leal

Coordenador Setorial do Centro

Técnico Científico - PUC-Rio

Rio de Janeiro, 31 de janeiro de 2014 
Todos os direitos reservados. É proibida a reprodução total ou parcial do trabalho sem autorização da universidade, do autor e do orientador.

\section{Ítalo Linhares Salomão}

Graduou-se em Engenharia Civil na Universidade de Fortaleza (Ceará, Brasil) em 2011. Trabalhou na área de projetos de estruturas de concreto armado e protendido na empresa Structurale. Desenvolveu junto com os seus orientadores durante o Mestrado modelos representativos de lajes nervuradas.

Ficha Catalográfica

Salomão, Ítalo Linhares

Análise numérica da eficiência de lajes nervuradas tridirecionais / Ítalo Linhares Salomão ; orientadora: Marta de Souza Lima Velasco ; co-orientadora: Elisa Dominguez Sotelino. - 2014.

107 f. il. (color.) ; $30 \mathrm{~cm}$

Dissertação (mestrado)-Pontifícia Universidade Católica do Rio de Janeiro, Departamento de Engenharia Civil, 2014. Inclui bibliografia

1. Engenharia civil - Teses. 2. Elementos finitos. 3. Laje nervurada. 4. Laje nervurada rotacionada. 5. Laje nervurada tridirecional. I. Velasco, Marta de Souza Lima. II. Sotelino, Elisa Dominguez. III. Pontifícia Universidade Católica do Rio de Janeiro. Departamento de Engenharia Civil. IV. Título. 
Dedico este trabalho a Edna Salomão, pelo apoio dado através do amor incondicional de mãe. 


\section{Agradecimentos}

Aos meus pais, irmã e cunhado que decidiram apoiar minhas decisões e me guiar através das incertezas.

Aos que inicialmente e continuamente cultivaram junto comigo a paixão pela engenharia civil, dentre elas cito Cássio, Georgiana e Anderson.

Aos amigos da Pós-Graduação que tão rapidamente se tornaram uma segunda família em uma cidade até então estranha, aos Snakes (Helvio, Graciele e Patrick), por uma irmandade jamais esperada, tendo posteriormente agregado mais pessoas como Carlos e Magno.

A todos aqueles que me acompanharam fora da faculdade, Wetter, Duan, Elida, Luiz, Tia Ana, Gisele e Leonardo, a quem tem me auxiliado de uma maneira singular, se mostrando uma pessoa que desejo ter ao meu lado sempre.

Às professoras Marta Velasco e Elisa Sotelino pela orientação de forma tão competente e afetuosa tornando esse processo mais fluido.

Aos que me transmitiram ética e profissionalismo, além de todo o conhecimento, agradeço a Eduardo Leite, Letícia Leite e Elaine Ponte.

A empresa Impacto Protensão, por manter as portas abertas para o desenvolvimento de novas pesquisas.

Ao CNPq e à PUC-Rio, pelos auxílios concedidos durante o curso de mestrado. 


\section{Resumo}

Salomão, Ítalo Linhares; Velasco, Marta de Souza Lima (Orientador); Sotelino, Elisa Dominguez (Co-Orientador). Análise numérica da eficiência de lajes nervuradas tridirecionais. Rio de Janeiro, 2013, 107pp. Dissertação de Mestrado - Departamento de Engenharia Civil, Pontifícia Universidade Católica do Rio de Janeiro.

As lajes nervuradas quando comparadas às lajes maciças apresentam redução do volume de concreto, não comprometem a eficiência da estrutura e permitem a construção de lajes mais econômicas e com maiores vãos. Este trabalho tem como objetivo verificar o comportamento de três tipos de lajes nervuradas: a laje nervurada tradicional, a laje nervurada rotacionada e a laje nervurada tridirecional. Na primeira fase deste trabalho foi realizado um estudo comparativo de vários modelos usando diferentes tipos de elementos, a fim de determinar aquele que melhor representa o comportamento das lajes nervuradas. O modelo selecionado utiliza elementos de casca para representar a capa de concreto e elementos de viga para representar as nervuras, ambos com seis graus de liberdade por nó. Elementos de ligação rígida foram usados para conectar os elementos de casca e os de viga a fim de capturar a posição relativa entre a capa e as nervuras. Uma vez selecionado o modelo, foi desenvolvido um estudo dos sistemas bidirecional, rotacionado e tridirecional, no regime elástico-linear. Os resultados encontrados através do programa de elementos finitos Robot permitiram comparar os três tipos de lajes em termos dos deslocamentos obtidos no Estado Limite de Serviço, da quantidade de aço determinada através do dimensionamento no Estado Limite Último, e do volume de concreto. As lajes nervuradas tradicionais apresentaram um comportamento estrutural melhor, com lajes mais rígidas e mais econômicas sob o ponto de vista da quantidade de materiais utilizados.

\section{Palavras-chave}

Elementos Finitos; Laje Nervurada; Laje Nervurada Rotacionada; Laje Nervurada Tridirecional. 


\section{Abstract}

Salomão, Ítalo Linhares; Velasco, Marta de Souza Lima (Advisor); Sotelino, Elisa Rodrigues (Co-Advisor). Numerical analysis of the efficiency of three-way slabs. Rio de Janeiro, 2013, 107pp. MSc. Dissertation - Departamento de Engenharia Civil, Pontifícia Universidade Católica do Rio de Janeiro.

When compared to flat slabs, the waffle slabs reduce the volume of concrete, do not compromise the efficiency of the structure and also allow the construction of more economical slabs with longer spans. This study intends to investigate the behavior of three types of waffle slabs: a traditional waffle slab, a rotated ribbed slab and three-way slab. In the first part of this study, it was carried out a comparative analysis of various models using different types of finite element techniques in order to determine which one best represents the behavior of waffle slabs. The selected model uses shell elements to represent the concrete cover and beam elements to represent the ribs, both with six degrees of freedom per node. Rigid link elements were used to connect the shell elements and the beam elements in order to capture the relative position between the concrete cover and the ribs. Once the model was selected, a study of two-way, three-way and rotational systems were developed in the linear elastic regime. The results found using the finite element program Robot allowed the comparison between the three types of slabs in terms of, displacements obtained from the Service Limit State, amount of steel determined by designing in the Ultimate Limit State and volume of concrete. The traditional ribbed slabs had an overall better structural behavior, resulting in slabs that are more rigid and more economical from the point of view of the amount of materials used.

\section{Keywords} Slabs.

Finite Elements; Waffle Slabs, Rotated Waffle Slabs, Three-way Waffle 


\section{Sumário}

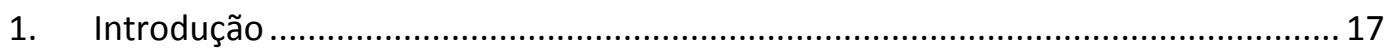





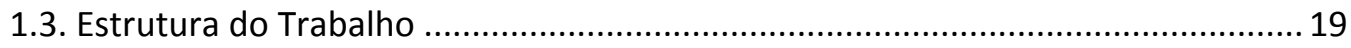

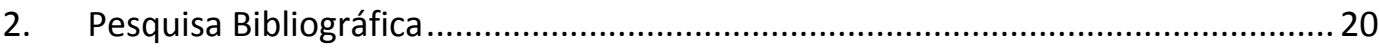

2.1. Considerações Gerais Sobre Lajes .......................................................... 20

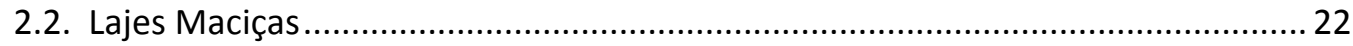

2.2.1. Considerações Gerais ........................................................................ 22

2.2.2. Prescrições Normativas (NBR 6118:2007) ............................................... 23

2.3. Lajes Nervuradas ................................................................................... 24

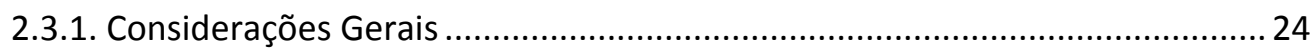

2.3.2. Prescrições Normativas (NBR 6118:2007) ............................................ 26

2.4. Lajes Tridirecionais ................................................................................. 26

2.4.1. Considerações Gerais ................................................................... 26

2.4.2. Método Construtivo e Detalhamento ................................................ 30

2.4.3. Lajes Contínuas Ligadas por Vigas Faixas Nervuradas ................................ 31

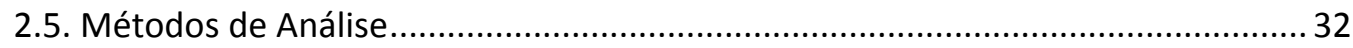

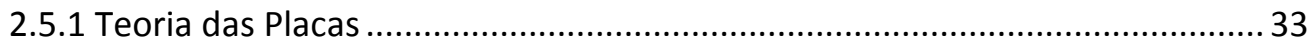

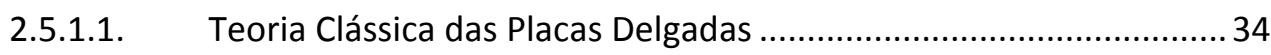

2.5.1.2. Momento em uma Placa Anisotrópica................................................. 35

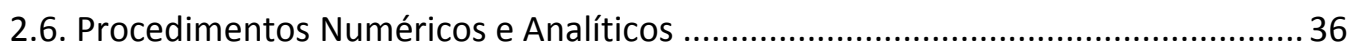

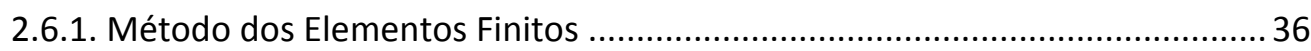

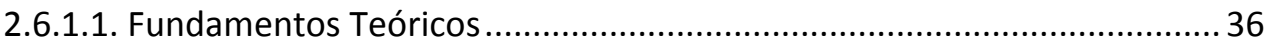

2.6.1.2. Elementos e Convergência ......................................................... 37

2.6.1.3. Método dos Elementos Finitos Baseado em Deslocamentos ................. 39

2.6.1.4. Integração Numérica por Pontos de Gauss........................................ 42

2.6.2. Grelha Equivalente ................................................................. 43

2.6.3. Métodos Empíricos ....................................................................... 45

2.7. Programas Computacionais para Análise de Estruturas ...................................46

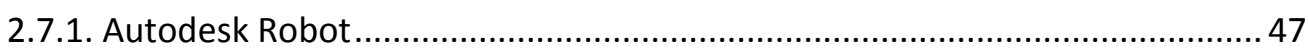

3. Modelagem por Elementos Finitos ......................................................... 48

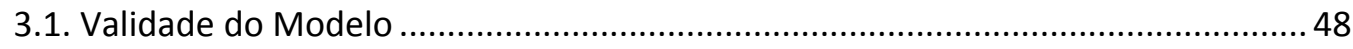




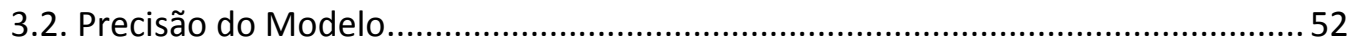

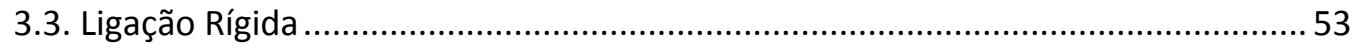

3.4. Resultados do Estudo de Convergência ............................................................. 56

4. Estudo do Comportamento de Lajes Nervuradas ....................................................66

4.1. Análise Numérica de Laje Nervurada Simplesmente Apoiada ..............................67

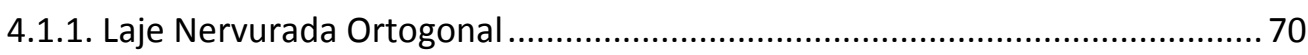





4.2. Análise Numérica de Lajes Nervuradas com Diversas Condições de Apoio............ 77

4.3. Análise Numérica de Lajes Contínuas Ligadas por Vigas Faixas Nervuradas ..........83

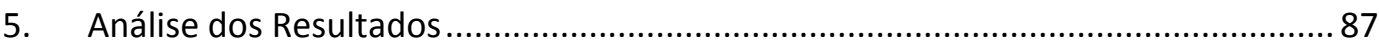

5.1. Análise dos Resultados para Lajes Simplesmente Apoiada ...................................8 87

5.2. Análise dos Resultados para Lajes com Diversas Condições de Apoio ...................92

5.3. Análise Numérica de Lajes Contínuas ligadas por Vigas Faixas Nervuradas ...........97

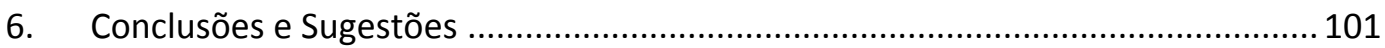

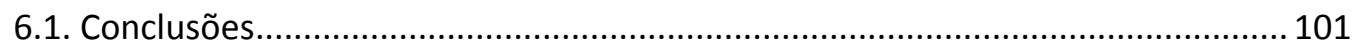

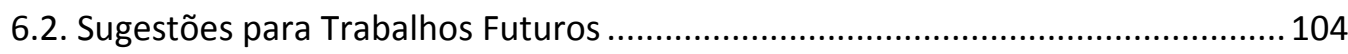

Referências Bibliográficas ........................................................................................... 106 


\section{Lista de Figuras}

Figura 2.1 - Laje Lisa, Reinforced Concrete Slabs [10] ................................. 22

Figura 2.2 - Laje cogumelo, Reinforced Concrete Slabs [10] ......................... 23

Figura 2.3 - Laje nervurada ..................................................................... 25

Figura 2.4 - Modulação da forma de uma laje tridirecional, Análise

Tridirecional em Lajes Nervuradas Protendidas [12] ...................................... 27

Figura 2.5 - Sistema de escoramento de uma laje tridirecional ....................... 30

Figura 2.6 - Laje nervurada tridirecional, Sistema Construtivo Tridirecional para Construção de Lajes Nervuradas [3] ........................................................ 31

Figura 2.7 - Laje nervurada tridirecional .................................................. 32

Figura 2.8 - Corpo livre a um ângulo $\alpha$........................................................ 34

Figura 2.9 - Cálculo do momento por nervura através do momento por unidade de comprimento, Theory of plates and shells [13]

Figura 3.1 - Forma da Laje nervurada

Figura 3.2 - Planta de locação da área de carregamento

Figura 3.3 - Modelos de viga com e sem excentricidade, Análise numérica de

lajes nervuradas por meio do método dos elementos finitos [6] 55

Figura 3.4 - Laje nervurada gerada pelo Modelador TQS 56

Figura 3.5 - Deslocamento obtido pelo Modelador TQS 57

Figura 3.6 - Modelo de casca e viga sem ligações rígidas 57

Figura 3.7 - Malha de 25x25 cm² para o modelo de casca e viga sem ligações rígidas 58

Figura 3.8 - Modelo de casca e viga com ligações rígidas 58 
Figura 3.9 - Modelo de elementos sólidos

Figura 3.10 - Planta de locação dos pontos de instrumentação

Figura 3.11 - Deslocamentos obtidos através do modelo com elementos de casca e viga sem consideração do offset

Figura 3.12 - Deslocamentos obtidos através do modelo com elementos de casca e viga com consideração do offset

Figura 3.13 - Deslocamentos obtidos através do modelo com elementos

sólidos 61

Figura 3.14 - Gráfico comparativo dos deslocamentos 62

Figura 4.1 - Geometria das formas da laje tipo 59

Figura 4.2 - Laje de referência 1.1, Marcus caso 1 - 6x6 m² $(\lambda=1)$ 70

Figura 4.3 - Laje de referência 2.1, Marcus caso 1 - 6x4 m² $(\lambda=1,5)$ 70

Figura 4.4 - Laje de referência 3.1, Marcus caso 1 - 6x3 m² $(\lambda=2)$ 71

Figura 4.5 - Momentos principais nas direções x e y, $\lambda=1$ 71

Figura 4.6 - Laje de referência 1.2, Marcus caso 1 - 6x6 m² $(\lambda=1)$ 74

Figura 4.7 - Laje de referência 2.2, Marcus caso 1 - 6x4 m² $(\lambda=1,5)$ 74

Figura 4.8 - Laje de referência 3.2, Marcus caso 1 - 6x3 m² $(\lambda=2)$ 74

Figura 4.9 - Laje de referência 1.3, Marcus caso 1 - 6x6 m² $(\lambda=1)$................ 76

Figura 4.10 - Laje de referência 2.3, Marcus caso 1 - 6x4 m² $(\lambda=1,5)$........... 76

Figura 4.11 - Laje de referência 3.3, Marcus caso 1 - 6x3 m² $(\lambda=2) \ldots \ldots \ldots \ldots \ldots . . . . .76$

Figura 4.12 - Lajes de referência no caso 2 de Marcus .................................... 79

Figura 4.13 - Lajes de referência no caso 4 de Marcus ................................... 79

Figura 4.14 - Lajes de referência no caso 5 de Marcus .................................... 80

Figura 4.15 - Lajes de referência no caso 7 de Marcus .................................... 80 
Figura 4.16 - Lajes de referência no caso 9 de Marcus

Figura 4.17 - Lajes de referência no caso 4 de Marcus

Figura 5.1 - Gráfico comparativo entre deslocamentos máximos no caso 1 .... 87

Figura 5.2 - Gráfico comparativo entre peso de aço nas nervuras no caso 1 .... 89

Figura 5.3 - Gráfico comparativo entre volume de concreto das nervuras no caso 1

Figura 5.4 - Gráfico comparativo entre deslocamentos máximos

Figura 5.5 - Gráfico comparativo entre peso de aço nas nervuras

Figura 5.6 - Gráfico comparativo entre volume de concreto das nervuras 95

Figura 5.7 - Deslocamentos da laje bidirecional 97

Figura 5.8 - Deslocamentos da laje rotacionada 97

Figura 5.9 - Deslocamentos da laje com faixas nervuradas 98

Figura 5.10 - Gráfico comparativo entre deslocamentos máximos 98

Figura 5.11 -Gráfico comparativo entre peso de aço das nervuras e vigas faixa 99 Figura 5.12 - Gráfico comparativo entre volume de concreto das nervuras e vigas faixa 100 


\section{Lista de Tabelas}

Tabela 3.1 - Quadro comparativo da convergência dos deslocamentos,

Análise numérica do comportamento de pavimentos constituídos de lajes lisas de concreto protendido [9] .......................................................................... 53

Tabela 3.2 - Quadro comparativo dos deslocamentos nos diversos modelos estudados

Tabela 3.3 - Quadro comparativo dos deslocamentos entre modelos estudados

Tabela 3.4 - Quadro comparativo dos deslocamentos obtidos em um modelo com variação de malha

Tabela 3.5 - Quadro apresentando a quantidade de nós nos diversos modelos estudados

Tabela 4.1 - Propriedades mecânicas dos materiais empregados

Tabela 4.2 - Deslocamentos, peso de aço e volume de concreto para lajes ortogonais, no caso 1

Tabela 4.3 - Verificação da tensão de compressão das bielas, no caso 1

Tabela 4.4 - Deslocamentos, peso de aço e volume de concreto para lajes

rotacionadas, no caso 1

Tabela 4.5 - Verificação da tensão de compressão das bielas, no caso 1

Tabela 4.6 - Deslocamentos, peso de aço e volume de concreto para lajes tridirecionais, no caso 1

Tabela 4.7 - Verificação da tensão de compressão das bielas, no caso 1 .......... 77

Tabela 4.8 - Deslocamentos, peso de aço e volume de concreto para lajes ....... 82

Tabela 4.9 - Verificação da tensão de compressão das bielas 
Tabela 4.10 - Deslocamentos, peso de aço e volume de concreto para lajes .... 86

Tabela 4.11 - Verificação da tensão de compressão das bielas ......................... 86

Tabela 5.1 - Comparação entre deslocamentos máximos no caso 1 ................ 88

Tabela 5.2 - Comparação entre peso de aço nas nervuras no caso 1 ................ 89

Tabela 5.3 - Comparação entre volume de concreto das nervuras no caso 1 .... 91

Tabela 5.4 - Comparação entre deslocamentos máximos ................................. 93

Tabela 5.5 - Comparação entre peso de aço nas nervuras ................................ 94

Tabela 5.6 - Comparação entre volume de concreto das nervuras .................... 96

Tabela 5.7 - Comparação entre deslocamentos máximos ................................. 98

Tabela 5.8 - Comparação entre peso de aço das nervuras e vigas faixas ........... 99

Tabela 5.9 - Comparação entre volume de concreto das nervuras e vigas

faixas 


\section{Lista de Símbolos}

\section{Letras Romanas Maiúsculas}

P $\quad$ Força externa

N Função de forma

G Módulo de elasticidade transversal

q Carga imposta na placa ou na barra

A Área da seção transversal

F Força axial

$V_{x}, V_{y} \quad$ Força Cortante

E Módulo de elasticidade ou módulo de Young

\section{Letras Romanas Minúsculas}

$m_{x}, m_{y}, m_{x y} \quad$ Momento

u' Deslocamento axial

k Matriz de rigidez

h $\quad$ Espessura da placa

W

Deflexão da placa na direção do carregamento no ponto 


\section{Letras Gregas}

$v \quad$ Coeficiente de Poisson

$\Omega \quad$ Trabalho exercido pelas forças externas

$\sigma_{x}, \sigma_{y}, \tau_{x y} \quad$ Tensão

$\varepsilon_{x}, \varepsilon_{y}, \varepsilon_{x y} \quad$ Deformação especifica

$\lambda$ Relação entre vãos da laje

$\Pi \quad$ Energia potencial

U Energia Interna ou energia de deformação

\section{Lista de Abreviaturas}

MEF Método dos Elementos Finitos

ELS Estado Limite de Serviço

ELU Estado Limite Último

GUI Graphical User Interface

BIM Building Information Modeling

GDL Grau de Liberdade

MRD Método da Rigidez Direta

EPE Energia Potencial Estacionária

NBR Norma Brasileira Registrada 